\title{
Morfologia e função fagocitária de implante esplênico autógeno regenerado em $\operatorname{ratos}^{1}$
}

\author{
Morphology and phagocytic function of regenerated autogenous splenic implant in rats
}

\author{
Ruy Garcia Marques², Andy Petroianu ${ }^{3}$, Janice Mery Chicarino de Oliveira Coelho ${ }^{4}$, Margareth Crisóstomo Portela ${ }^{5}$ \\ 1. Trabalho realizado no Laboratório da Disciplina de Técnica Operatória e Cirurgia Experimental da Faculdade de Ciências Médicas da \\ Universidade Estadual do Rio de Janeiro (UERJ). \\ 2. Professor Doutor do Departamento de Cirurgia Geral da Faculdade de Ciências Médicas da UERJ. \\ 3. Professor Titular do Departamento de Cirurgia da Faculdade de Medicina da UFMG. \\ 4. Professor Assistente do Departamento de Patologia e Laboratórios da Faculdade de Ciências Médicas da UERJ. \\ 5. Pesquisador Associado do Departamento de Administração e Planejamento em Saúde da Escola Nacional de Saúde Pública Sérgio Arouca - \\ FIOCRUZ.
}

\begin{abstract}
RESUMO
Objetivo: O objetivo deste trabalho é analisar a regeneração morfológica de tecido esplênico auto-implantado em ratos Wistar, verificando a função fagocitária bacteriana de seus macrófagos. Métodos: Utilizou-se um modelo experimental com ratos jovens e adultos, de ambos os sexos, submetidos a esplenectomia total combinada com auto-implante de fatias de toda a massa esplênica no omento maior. Dezesseis semanas após, os animais foram inoculados por via intravenosa com suspensão de Escherichia coli AB1157 e, após 20 minutos, foram mortos por dose letal de halotano, sendo submetidos a laparotomia para retirada dos autoimplantes esplênicos. A análise estatística foi realizada com o teste t de Student, com ênfase na comparação da massa de autoimplante esplênico regenerada entre animais jovens e adultos de ambos os sexos. Resultados: Ocorreu regeneração do autoimplante esplênico em todos os animais. Machos jovens e fêmeas adultas apresentaram maior percentual de regeneração. Observouse aspecto morfológico microscópico semelhante em todos os animais. O tecido esplênico regenerado mostrou as polpas vermelha e branca, com desarranjo arquitetural moderado, bem como folículos linfóides. Os vasos sangüíneos mostravam paredes preservadas, sem sinais de vasculite ou trombose. Foram encontrados macrófagos contendo grumos de bactérias, bem como macrófagos contendo pigmento de hemossiderina intracitoplasmáticos. Conclusão: O auto-implante esplênico, no omento maior, em ratos, adquire a arquitetura macro e microscópica de um baço normal, de dimensão menor e preserva a função fagocitária bacteriana. Descritores: Baço. Transplante Autólogo. Regeneração. Fagocitose. Esplenectomia.
\end{abstract}

\begin{abstract}
Purpose: To analyze the morphologic regeneration of autotransplanted splenic tissue in Wistar rats and to determine the bacterial phagocytic function of their macrophages. Methods: We utilized an experimental model including young and adult rats, of both sexes, submitted to total splenectomy combined with autotransplantation in the greater omentum of slices of the whole mass of spleen. Sixteen weeks later animals were intravenously inoculated with a suspension of Escherichia coli AB1157, and twenty minutes later killed with lethal dose of halothane and submitted to laparotomy for splenic autotransplants retrieval. Data were analyzed statistically by de Student-t test, with emphasis on the comparison of the extent level of autotransplanted splenic mass regeneration between young and adult animals of both sexes. Results: There was regeneration of autotransplanted splenic tissue in all animals. Young males and adult females presented greater regeneration. A similar morphological aspect among all animals was observed, with splenic tissue showing red and white pulps with a moderate architectural disarrangement, as well as lymphoid follicles. Blood vessels showed preserved walls, with no signs of vasculitis or thrombosis. Macrophages containing bacterial aggregates were observed, as well as macrophages with hemosiderin pigments inside the cytoplasm. Conclusion: The present results suggest that splenic autotransplant in the greater omentum of the rat acquires the macro- and microscopic architecture of a normal spleen, with reduced dimensions, and preserves bacterial phagocyte function.
\end{abstract}

Key words: Spleen. Transplantation, Autologous. Regeneration. Phagocytosis. Splenectomy.

\section{Introdução}

Pacientes submetidos a esplenectomia total, em qualquer faixa etária e por qualquer indicação, apresentam risco aumentado de morte por infecção fulminante pós-esplenectomia (IFPE). Quando existe hiposplenia, asplenia funcional não- 
cirúrgica, asplenia congênita ou outras afecções esplênicas, também há aumento de risco de sepse fulminante. ${ }^{1}$

Sabe-se, desde o final do século XIX, que o baço apresenta capacidade de regeneração. Griffini e Tizzoni ${ }^{2}$, em 1883, foram os primeiros a mostrar áreas de regeneração esplênica espontânea no peritônio de cães submetidos a esplenectomia. Poucos anos mais tarde, esse fato foi observado em humanos por Albrecht (1896) e Schilling (1907). ${ }^{3}$ Em 1939, Buchbinder e Lipkoff ${ }^{3}$ sugeriram a denominação de esplenose para o tecido esplênico regenerado espontaneamente dentro da cavidade abdominal, após trauma do baço. Em 1978, Pearson e col. ${ }^{4}$ verificaram a presença de função esplênica em crianças com esplenose, após esplenectomia por trauma. Mediante avaliação por cintilografia, esses autores constataram que havia tecido esplênico residual regenerado em $26 \%$ a $64 \%$ dos pacientes, e, nesses casos, não foram encontrados corpúsculos de Howell-Jolly ou hemácias senescentes no sangue periférico, como usualmente ocorre em condições de asplenia.

Com base na correlação existente entre sepse e esplenectomia e nos achados clinicopatológicos dos implantes esplênicos espontâneos, o auto-implante esplênico heterotópico passou a ser considerado como uma opção na tentativa de preservar as funções do baço, nos casos em que fosse inevitável a sua retirada. ${ }^{4-6}$

Após período inicial de necrose, o implante esplênico autógeno é capaz de regenerar-se, mas, para manter função adequada, precisa drenar para o sistema porta. ${ }^{2,6-8}$ Em local adequado, forma nódulos similares ao baço normal. Esses neobaços, circundados por fina cápsula fibrosa, contêm polpas vermelha e branca, com a estrutura de suprimento sangüíneo similar à do órgão íntegro. ${ }^{2,6-9}$ A neovascularização origina-se de ramos de artérias circunvizinhas ao local da implantação no caso de implante omental, provém das artérias gastroomentais, com drenagem venosa para a veia porta, à semelhança do baço in situ -, com orientação centrípeta em relação ao implante, iniciando poucos dias após esse procedimento. ${ }^{8,10}$

Geralmente, à implantação esplênica segue-se necrose quase completa, permanecendo viável apenas um fragmento mínimo, que se regenera em tecido esplênico com estrutura microscópica quase indistinguível do órgão original. Diversos estudos já mostraram a ocorrência dessa fase de necrose no rato, camundongo, coelho, porco e no homem..$^{8,10,12,13}$ Em roedores, a estrutura histológica do tecido esplênico regenerado é tida como comparável ao tecido esplênico normal, ${ }^{4,11}$ embora existam diferenças relativas à idade dos animais empregados. ${ }^{2,5,7,13} \mathrm{O}$ processo de regeneração inicia na camada periférica, que não acompanha o processo degenerativo da parte central do implante, e, gradualmente, substitui a zona central necrótica. Observa-se que, muitas vezes, a zona periférica é mais diferenciada que a parte central e que pequenos implantes regeneram-se em tempo mais curto do que os que contêm uma grande quantidade de tecido. Nestes, a zona periférica pode desenvolver-se em tecido esplênico normal e o centro constituir-se apenas de uma camada de células conjuntivas proliferativas penetrando a zona necrótica. ${ }^{7,8,10}$

O auto-implante esplênico parece constituir a única alternativa para preservação de tecido esplênico após esplenectomia total. Todavia, a regeneração tissular não significa, necessariamente, que haja recuperação da função imune. O objetivo deste trabalho é analisar a regeneração morfológica de tecido esplênico auto-implantado, em ratos jovens e adultos, de ambos os sexos, verificando a função fagocitária bacteriana de seus macrófagos.

\section{Métodos}

Foram utilizados 32 ratos Wistar albinos, 13 machos e 19 fêmeas. Os animais foram divididos em dois grupos: I - ratos jovens, com peso variando entre $100 \mathrm{~g}$ e $150 \mathrm{~g}$ (cinco machos e 14 fêmeas); e II - ratos adultos, com peso variando entre $250 \mathrm{~g}$ e $300 \mathrm{~g}$ (oito machos e cinco fêmeas). Os animais foram colocados em gaiolas apropriadas, máximo de cinco por gaiola, e receberam ração apropriada para ratos e água ad libitum.

Este trabalho foi aprovado pelo Comitê de Ética em Pesquisa Animal do Laboratório de Cirurgia Experimental da Faculdade de Ciências Médicas da Universidade do Estado do Rio de Janeiro. Todos os procedimentos seguiram, rigorosamente, a regulamentação existente sobre experimentação com animais.

Após jejum de seis horas, os animais foram submetidos a anestesia inalatória com halotano, tricotomia abdominal e antisepsia com iodopovidine.

Por meio de laparotomia mediana supra-umbilical, procedeu-se à esplenectomia total. O baço foi pesado e seccionado, transversalmente, em cinco fatias, cada uma com cerca de $2 \mathrm{~mm}$ de espessura. As secções esplênicas, correspondentes à massa esplênica total, foram implantadas no omento maior, mediante sutura contínua, com fio de ácido poliglicólico 4-0. Os pontos foram dados alternadamente, no omento e no tecido esplênico, para que houvesse interposição de tecido omental entre as fatias esplênicas. A laparorrafia foi realizada com sutura contínua, em dois planos (peritonioaponeurótico e pele), com fio de ácido poliglicólico 3-0.

Após 16 semanas do início do experimento, sob anestesia inalatória com halotano, realizou-se tricotomia cervical e abdominal, e anti-sepsia com iodopovidine. Através de cervicotomia transversa direita, dissecou-se a veia jugular interna, onde foram inoculados $0,2 \mathrm{ml}$ de suspensão contendo Escherichia coli, em concentração bacteriana correspondente a $10^{8}$ unidades formadoras de colônias (UFC). Depois de 20 minutos da inoculação, os animais foram mortos, com dose letal de halotano, e submetidos a laparotomia mediana, com retirada dos auto-implantes esplênicos que foram pesados e colocados em frascos contendo solução de formalina tamponada a $10 \%$. Processou-se o tecido em soluções crescentes de álcool e xilol; em seguida, ele foi incluído em blocos de parafina e cortado em fatias de $4 \mu$ de espessura. Foram preparadas lâminas, que foram submetidas à coloração com hematoxilina-eosina (HE) e Gram, e analisadas ao microscópio óptico.

A análise estatística foi realizada com o teste t de Student, com ênfase na comparação da massa de auto-implante esplênico regenerada (percentual de tecido esplênico recuperado após 16 semanas, em relação à massa esplênica implantada) 
entre animais jovens e adultos de ambos os sexos.

\section{Resultados}

Ocorreu regeneração do auto-implante esplênico em todos os animais. Entre os animais jovens, as médias relativas à massa implantada e à massa regenerada, bem como o percentual de regeneração, foram maiores para machos $(\mathrm{p}=0,0132$, $\mathrm{p}=0,0010, \mathrm{p}=0,595$, respectivamente). Para os animais adultos, não foi encontrada diferença entre as médias referentes à massa implantada em machos e fêmeas. Entretanto, fêmeas apresentaram maior massa regenerada e maior percentual de regeneração ( $p=0,0254, p=0,0152$, respectivamente) (Tabela 1$)$.

$\mathrm{Na}$ comparação de animais jovens vs. adultos, observou-se que as médias relativas à massa implantada e à massa regenerada foram maiores nos animais adultos (Tabela 2).

TABELA 1 - Comparação da regeneração da massa esplênica entre animais machos $(\mathrm{M})$ e fêmeas (F) de um mesmo grupo etário

\begin{tabular}{|c|c|c|c|c|c|c|c|}
\hline \multirow{3}{*}{ Grupo } & \multirow{3}{*}{ Sexo } & \multicolumn{2}{|c|}{ Massa implantada (g) } & \multicolumn{2}{|c|}{ Massa regenerada (g) } & \multicolumn{2}{|c|}{$\%$ recuperado / massa } \\
\hline & & & & & & total & \\
\hline & & Média & Teste t (p) & Média & Teste $t(p)$ & Média & Teste t (p) \\
\hline \multirow[t]{2}{*}{ Jovens } & $\mathbf{M}$ & 0,61 & $0,0132 *$ & 0,2 & $0,0010^{*}$ & 33,21 & $0,0595 *$ \\
\hline & $\mathbf{F}$ & 0,48 & & 0,15 & & 25,36 & \\
\hline \multirow[t]{2}{*}{ Adultos } & $\mathbf{M}$ & 0,69 & 0,6892 & 0,16 & $0,0254 *$ & 23,31 & $0,0152 *$ \\
\hline & $\mathbf{F}$ & 0,65 & & $\mathbf{0 , 3 1}$ & & 46,79 & \\
\hline
\end{tabular}

* Diferença significativa

TABELA 2 - Comparação da regeneração da massa esplênica entre animais jovens (I) e adultos(II)

\begin{tabular}{lcccc}
\hline Grupo & & Massa & Massa & \% recuperado \\
& & implantada (g) & regenerada (g) & / massa total \\
\hline I & Média & $\mathbf{0 , 5 1}$ & $\mathbf{0 , 1 4}$ & $\mathbf{2 7 , 4 3}$ \\
& DP & $\mathbf{0 , 1 0}$ & $\mathbf{0 , 0 7}$ & $\mathbf{1 1 , 6 7}$ \\
\hline II & Média & $\mathbf{0 , 6 7}$ & $\mathbf{0 , 2 2}$ & $\mathbf{3 2 , 3 4}$ \\
& DP & 0,10 & 0,12 & 17,46 \\
\hline I - II & Teste t & $\mathbf{0 , 0 0 0 2 *}$ & $\mathbf{0 , 0 8 0 1}$ & $\mathbf{0 , 3 6 3 3}$ \\
\hline DP - desvio padrão & & & \\
* Diferença significativa &
\end{tabular}


A Figura 1 ilustra a visão macroscópica do autoimplante esplênico regenerado em tecido omental, com um dos fragmentos assemelhando-se a um baço normal, de dimensão menor.

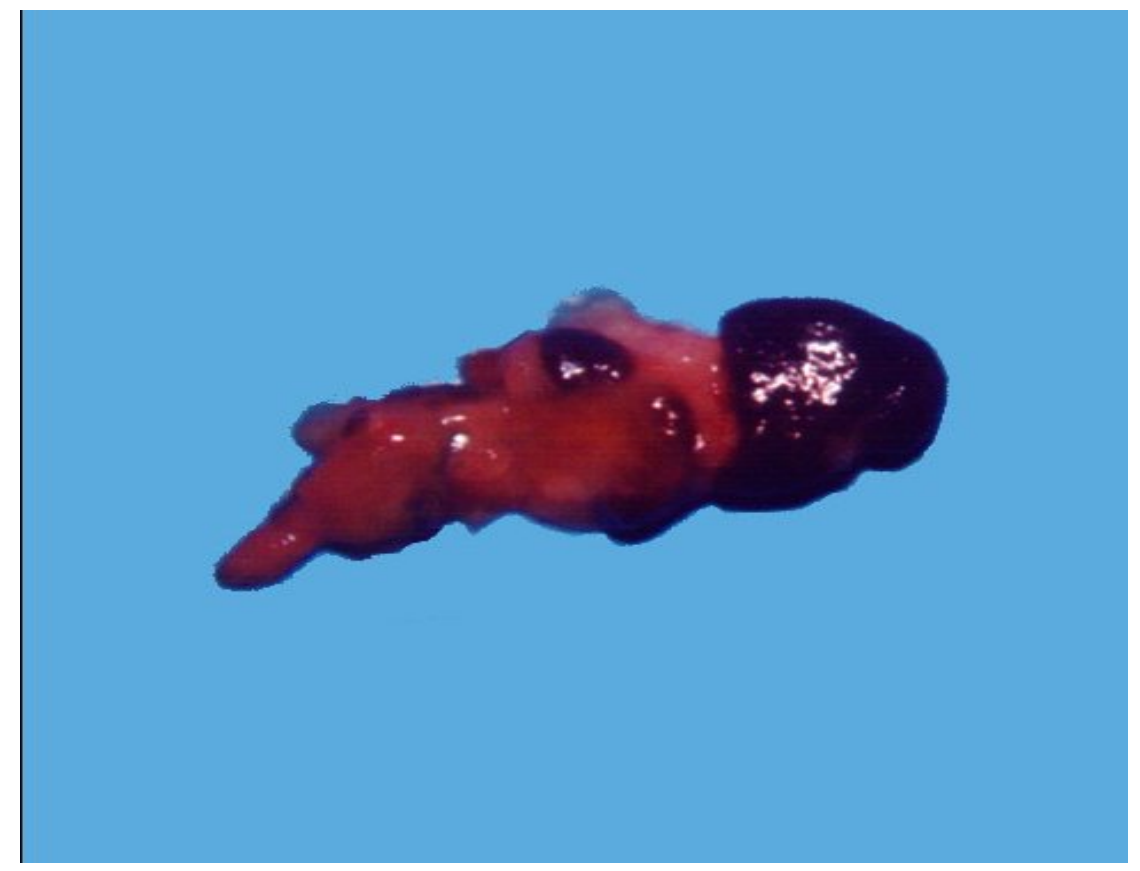

FIGURA 1 - Aspecto macroscópico de auto-implante esplênico regenerado em tecido omental

Ao exame microscópico, pela coloração com HE, observou-se aspecto morfológico semelhante em todos os animais. O tecido esplênico mostrava as polpas vermelha e branca, com desarranjo arquitetural moderado. Houve redução da polpa branca, porém com a presença de folículos linfóides. Também ocorreu diminuição da zona marginal, não sendo observados centros germinativos. Foram encontrados macrófagos contendo grumos de bactérias, bem como macrófagos contendo pigmento de hemossiderina intracitoplasmáticos, dispostos difusamente pelo parênquima esplênico. Os vasos sangüíneos apresentaram paredes preservadas, sem sinais de vasculite ou trombose. A Figura 2 ilustra a morfologia microscópica de um auto-implante esplênico regenerado, corado com $\mathrm{HE}$.

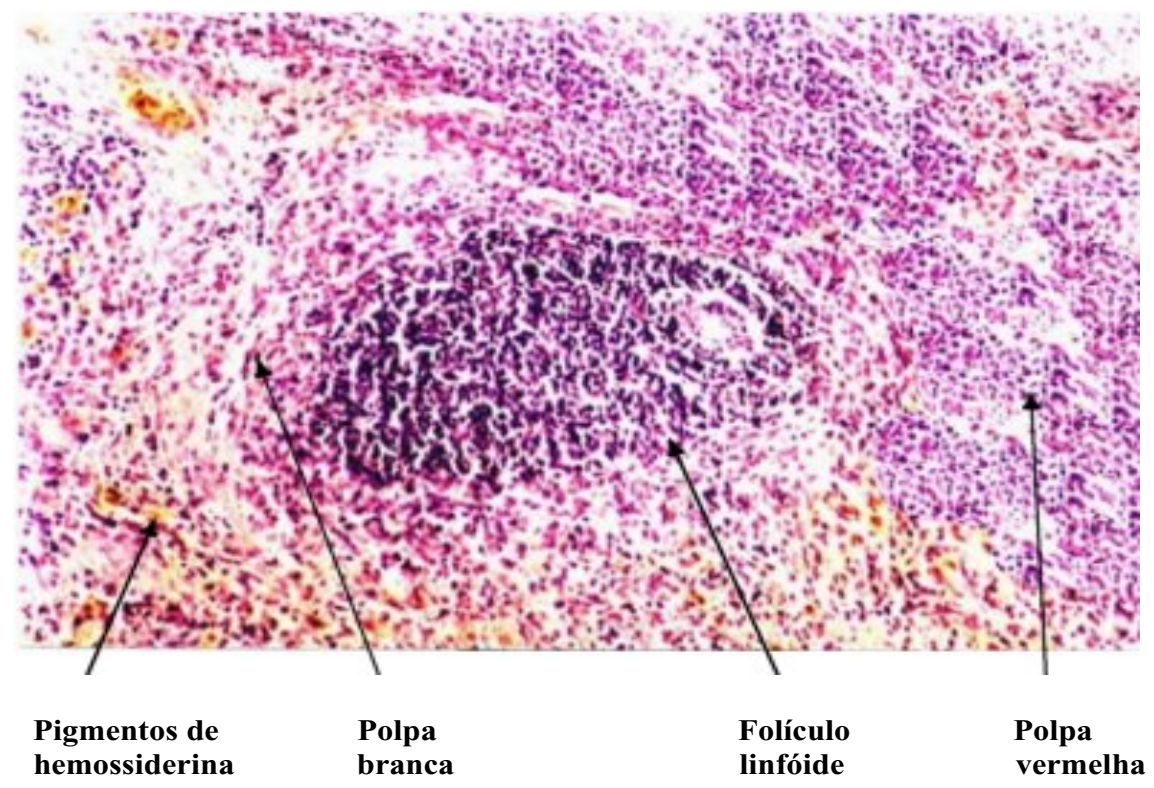

FIGURA 2 - Morfologia microscópica do auto-implante esplênico regenerado (HE- 20 x) 
As Figuras 3 e 4 mostram a morfologia microscópica corados com HE e Gram, respectivamente. de macrófagos com grumos bacterianos em seu citoplasma,

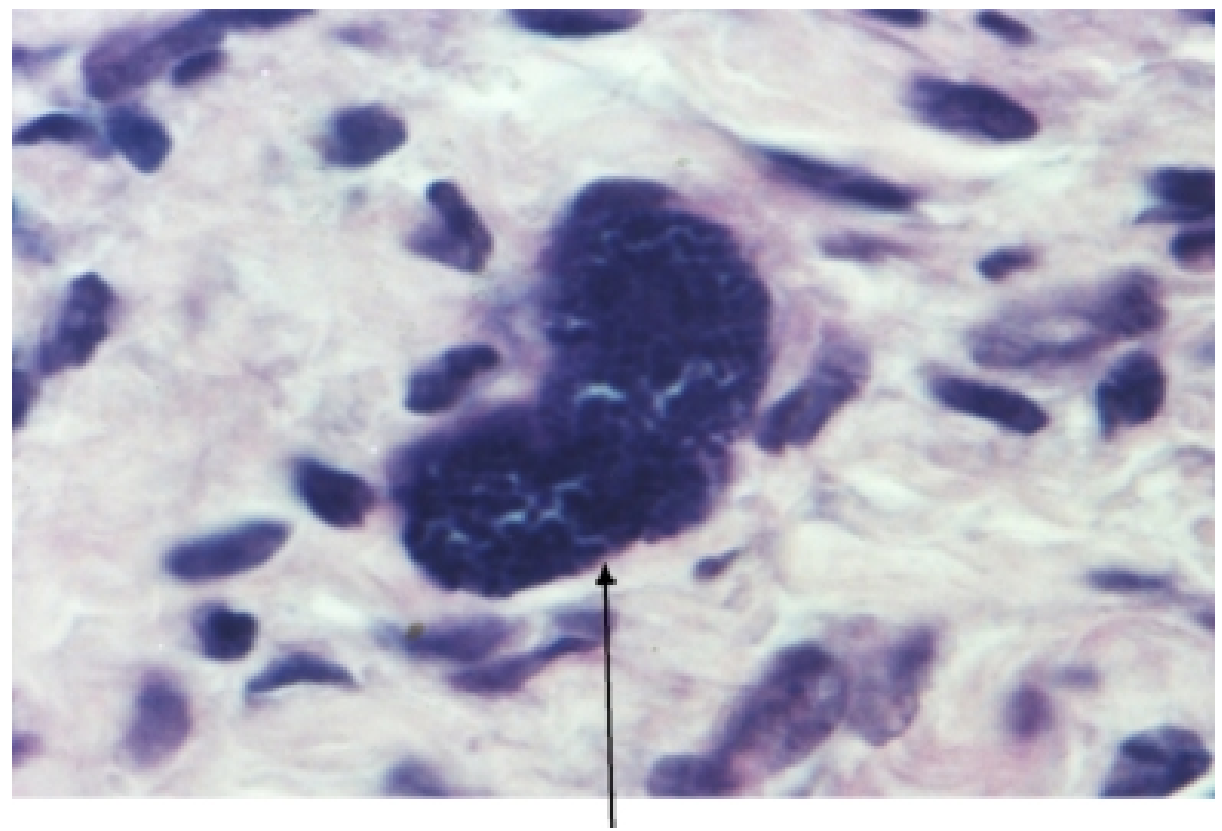

\section{Macrófago, mostrando grumos de bactérias em seu citoplasma}

FIGURA 3 - Grumos bacterianos no citoplasma de um macrófago (HE - 1.000 x)

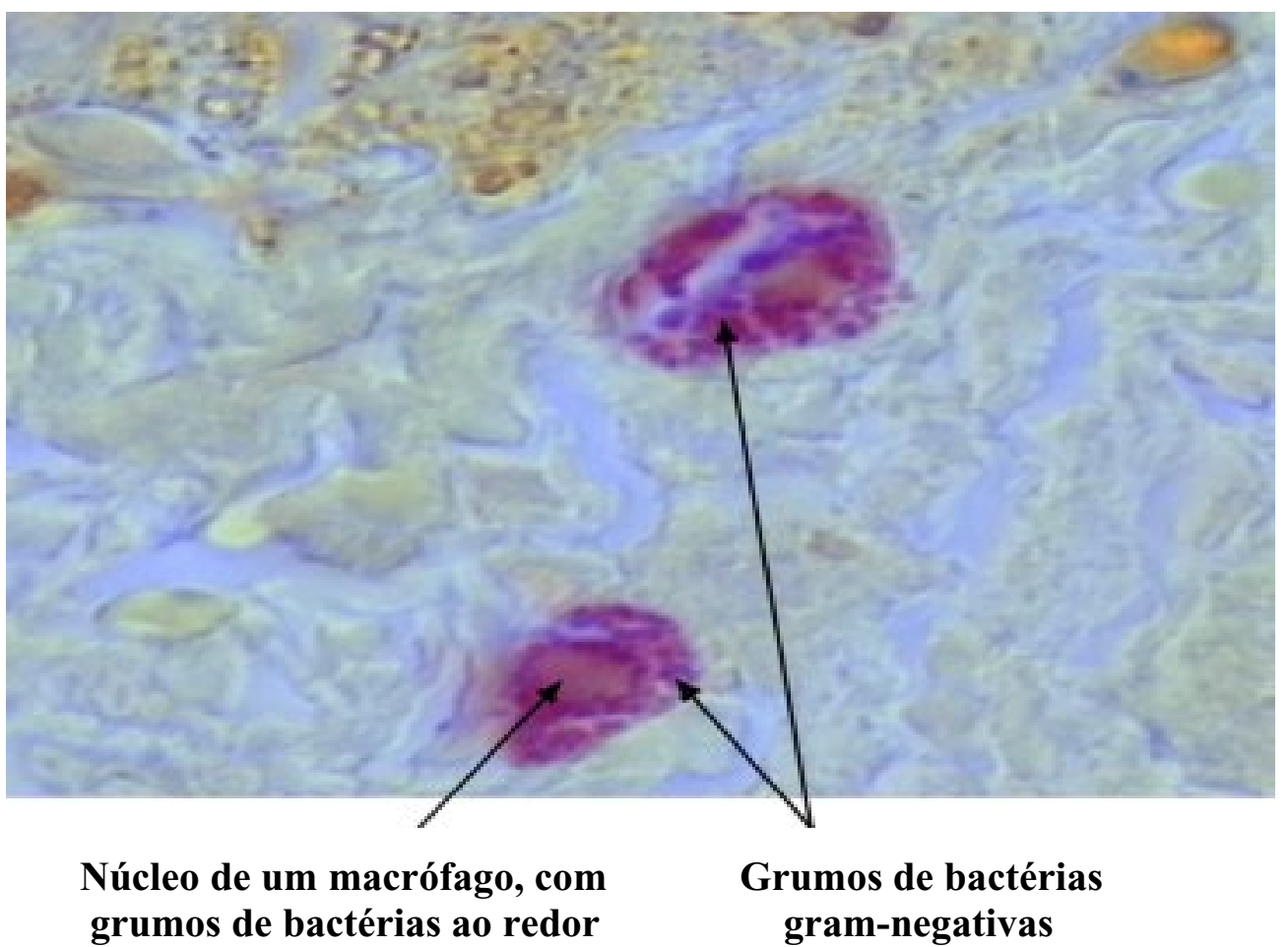

FIGURA 4 - Grumos de bactérias gram-negativas no citoplasma de macrófagos, ao redor de seu núcleo (Gram - 1.000x) 


\section{Discussão}

$\mathrm{Na}$ atualidade, existem fortes indícios de que dois importantes aspectos relativos ao auto-implante esplênico parecem estar estabelecidos: sua efetiva capacidade de regeneração e o melhor local para sua implantação. Diversos locais para o implante esplênico autógeno têm sido testados omento maior, tecido subcutâneo, bolsa mesentérica de intestino delgado, músculo, fígado (através da veia porta), pré-peritônio, retroperitônio, etc. Comparando estudos com as mesmas espécies animais e utilizando as mesmas técnicas, implantes intraperitoneais parecem crescer e funcionar melhor que os retroperitoneais e subcutâneos; particularmente, os omentais, com drenagem venosa para a veia porta, apresentam os melhores resultados. , $7,10,14^{2}$ Em humanos, os auto-implantes esplênicos têm sido realizados, quase que em sua totalidade, em bolsas no omento maior ${ }^{12,14}$ ou suturadas sobre o omento. ${ }^{6}$ Endossando esses resultados, todos os auto-implantes esplênicos que realizamos em omento maior, levaram à regeneração do tecido esplênico.

O auto-implante esplênico em animais jovens parece propiciar melhor regeneração e maior recuperação da atividade funcional que em adultos. ${ }^{2,7,8,9,13}$ Animais jovens, bem como crianças, apresentam sistema imunitário menos desenvolvido que os adultos. Por outro lado, quanto mais jovem o animal, maior a sua capacidade de regeneração tecidual, o que pode explicar a melhor recuperação funcional do implante. .,9,13 $^{-13}$

Conquanto a massa de tecido esplênico necessária para gerar função esplênica seja dependente da quantidade de tecido regenerada, não tendo relação com o número de fragmentos implantados, o mínimo de tecido esplênico necessário para que se observe função do baço - massa crítica - parece ser de $25 \%$ de um baço normal. ${ }^{5,6,9}$. O percentual de regeneração esplênica apresenta correlação direta com a massa implantada, tanto em animais jovens quanto em adultos. ${ }^{7}$ Como os ratos adultos possuem maior peso e, por conseguinte, maior massa esplênica, a quantidade de tecido esplênico implantado foi maior neles do que em jovens. Esse fato poderia explicar o maior percentual esplênico regenerado em animais adultos, embora os resultados obtidos não evidenciem diferença estatisticamente significante. Analisando cada faixa etária, machos jovens e fêmeas adultas apresentaram maiores médias de massa regenerada e de percentual de regeneração. Thalhamer e col. ${ }^{15}$ também encontraram regeneração diminuída em fêmeas jovens. Embora não haja relatos na literatura que correlacionem influência hormonal com regeneração de auto-implantes esplênicos, o fato de fêmeas jovens apresentarem menor percentual de regeneração, em comparação com o maior percentual encontrado em fêmeas adultas, pode ser eventualmente explicado pela ausência de regulação hormonal bem desenvolvida em animais jovens. Dessa forma, a maior liberação hormonal, após a maturação sexual das fêmeas, poderia favorecer a regeneração desses implantes.

A observação de aparente redução da polpa branca tem sido verificada em diversos trabalhos experimentais com ratos. ${ }^{11,15}$ Por outro lado, Iinuma e col. ${ }^{7}$ e Tavassoli e col. ${ }^{8}$ mostraram regeneração completa da polpa branca após cinco e
16 semanas, respectivamente. As razões para esses comportamentos diversos não são conhecidas, podendo ser, ao menos em parte, devidas à espécie animal e a critérios individuais de avaliação microscópica. A polpa branca, em comparação com a polpa vermelha, demora mais para regenerarse completamente, talvez porque a neovascularização do autoimplante se faça da periferia (polpa vermelha) para o centro (polpa branca). Existe ainda a possibilidade, segundo Petroianu ${ }^{16}$, de as polpas vermelha e branca serem duas estruturas distintas, que estão unidas como se fossem um único órgão, à semelhança do córtex e da medula supra-renal. Dessa forma, a sua regeneração também se faria independente uma da outra.

Os dados da literatura são bastante controversos no que se refere ao tempo necessário para que ocorra a regeneração anatômica do implante esplênico autógeno em ratos. Ele varia entre cinco a oito semanas, ${ }^{8,9}$ mas parece que somente após 16 semanas, o auto-implante assemelha-se a um baço normal. Provavelmente, a regeneração funcional também está presente após esse período.?

Utilizamos a linhagem selvagem de Escherichia coli AB1157, por ser a bactéria gram-negativa mais bem estudada e por fazer parte da flora intestinal normal, em humanos. É importante ressaltar que a $E$. coli é responsável por cerca de $12 \%$ dos casos de IFPE. ${ }^{1}$ As bactérias gram-negativas são também os principais agentes etiológicos de infecções em pacientes esplenectomizados idosos e debilitados por doenças crônicas.

Diversos estudos acerca do auto-implante esplênico têm mostrado que esse procedimento é simples, não se associa a grandes complicações e que sua utilização possibilita a recuperação de algumas funções do baço. ${ }^{2,7,13,15}$

Os resultados deste trabalho sugerem que o autoimplante esplênico, no omento maior, em rato, adquire a arquitetura macro e microscópica de um baço normal, de dimensão menor. A presença de pigmento de hemossiderina no interior de macrófagos pode ser atribuída à fagocitose de elementos sangüíneos decorrente de processo hemorrágico, durante a fase inicial da necrose do implante, ou à fagocitose de hemácias senescentes da corrente sangüínea.

Em particular, gostaríamos de enfatizar a presença de grumos intracitoplasmáticos de bactérias gram-negativas, ao redor de seu núcleo, o que comprova a regeneração da função fagocitária do tecido esplênico auto-implantado.

O modelo desenvolvido neste trabalho deverá ser empregado em ratos mais jovens - tanto recém-nascidos, como logo após o desmame - e mais velhos, visando à verificação da função fagocitária dos macrófagos do auto-implante esplênico regenerado em faixas etárias extremas. Da mesma forma, outras espécies animais, assim como outras bactérias, deverão ser testadas para ratificação de nossos achados. O intervalo de tempo decorrido entre o implante autógeno de tecido esplênico e a realização de estudos para comprovação de sua regeneração funcional também deverá ser modificado - reduzido e ampliado - no intuito de compreender melhor essa regeneração. 


\section{Conclusão}

O auto-implante esplênico, no omento maior, em ratos, adquire a arquitetura macro e microscópica de um baço normal, de dimensão menor e preserva a função fagocitária bacteriana.

\section{Referências}

1. Singer D. Postsplenectomy sepsis. Perspect Pediatr Pathol. 1973;1:285-311.

2. Holdsworth RJ. Regeneration of the spleen and splenic autotransplantation. Br J Surg. 1991;78:270-8.

3. Bubchbinder JH, Lipkoff CJ. Splenosis: multiple peritoneal splenic implant following abdominal injury: a report of a case and review of the literature. Surgery. 1939;6:927-34.

4. Pearson HA, Johnston D, Smith KA, Touloukian RJ. The born-again spleen: return of splenic function after splenectomy of trauma. N Engl J Med. 1978;298:1389-92.

5. Patel JM, Williams JS, Naim JO, Hinshaw JR. The effect of site and technique of splenic tissue reimplantation on pneumococcal clearance from the blood. J Pediatr Surg. 1986;21:877-80.

6. Resende V, Petroianu A. Estudo funcional tardio do auto-implante esplênico após trauma complexo do baço humano. Rev Col Bras Cir. 2001;28:165-70.

7. Iinuma H, Okinaga K, Sato S, Tomioka M, Matsumoto K. Optimal site and amount of splenic tissue for autotransplantation. J Surg Res. 1992;53:109-16.
8. Tavassoli M, Ratzan RJ, Crosby WH. Studies on regeneration of heterotopic splenic autotransplants. Blood. 1973;41:701-9.

9. Van Wyck DB, Witte MH, Witte CL, Thies AC Jr. Critical splenic mass for survival from experimental pneumococcemia. J Surg Res. 1980;28:14-7.

10. Sasaki K, Kiuchi Y, Sato Y, Yamamori S. Morphological analysis of neovascularization at early stages of rat splenic autografts in comparison with tumor angiogenesis. Cell Tissue Res. 1991;265:503-10.

11. Thalhamer J, Pimpl W, Pattermann M. The role of the spleen and splenic autotransplants in clearing experimental bacteremia caused by the gram-negative bacterium E. coli. Res Exp Med. 1986;186:229-38.

12. Patel JM, Williams JS, Shmigel B, Hinshaw JR. Preservation of splenic function by autotransplantation of traumatized spleen in man. Surgery. 1981;90:683-8.

13. Malangoni MA, Dawes LG, Droege EA, Rao SA, Collier BD, Almagro UA. Splenic phagocytic function after partial splenectomy and splenic autotransplantation. Arch Surg. 1985;120:275-8.

14. Marques RG, Petroianu A, Coelho JMCO, Portela MC. Regeneration of splenic autotransplants. Ann Hematol. 2002;81:622-6.

15. Thalhamer J, Leitner W, Kurz ME, Liaunigg A, Seifriedsberg M, Bergmann ES, Kaindl H, Pimpl W. Immunoarchitecture and specific functions of splenic autotransplants at different implantation sites. Eur Surg Res. 1992;24:22-36.

16. Petroianu A. Pós-operatório em cirurgias do baço. In: Petroianu A (ed.). O baço. 1.ed. São Paulo: CLR Balieiro Editores; 2003. p 28198.

\section{Agradecimentos}

Os autores agradecem ao Dr. Carlos Eduardo Rodrigues Caetano e ao Sr. Domingos Peçanha de Oliveira pelo auxílio na anestesia e no acompanhamento dos animais.

Correspondência

Conflito de interesse: nenhum

Fonte de financiamento: Fundação Carlos Chagas Filho de

Ruy Garcia Marques

Rua Clóvis Salgado, 280/104

22795-230 Rio de Janeiro - RJ

Tel/Fax: (21)2587-6859

rmarques@uerj.br

Recebimento: 03/08/2004

Revisão: 21/09/2004

Aprovação: 17/10/2004

\section{Como citar este artigo:}

Marques RG, Petroianu A,Coelho JMCO, Portela MC. Morfologia e função fagocitária de implante esplênico autógeno regenerado em ratos. Acta Cir Bras [serial online] 2004 Nov-Dez;19(6). Disponível em URL: http://www.scielo.br/acb [também em CDROM].

*Figuras coloridas disponíveis em www.scielo.br/acb 